\title{
KOMPUTERISASI AKUNTANSI PEMBELIAN KERTAS SECARA KREDIT BERBASIS WEB PADA CV CIPTA GRAFIKA
}

\author{
${ }^{1}$ Yeny Rostiani, ${ }^{2}$ Lila Setiyani ${ }^{\bowtie}$ \\ ${ }^{1}$ Program Studi Komputerisasi Akuntansi, STMIK ROSMA, Karawang, Indonesia \\ ${ }^{2}$ Program Studi Sistem Informasi, STMIK ROSMA, Karawang, Indonesia \\ Email: lila.setiyani@dosen.rosma.ac.id
}

DOI: https://doi.org/10.46880/jmika.Vol4No2.pp134-143

\begin{abstract}
CV Cipta Grafika is a company engaged in printing, for the raw material needs for printing this company buys in cash or credit. In this study, the researcher will discuss the process of purchasing printing materials on credit, because in this process the existing applications have not provided maximum results, namely, there are often errors in the presentation of data or information. The researcher will create a web-based credit purchase and debt recording system with MySQL as the database. The output of this system is the payment of obligations to the supplier which will be due and the supplier's debt recording report can be monitored. It is hoped that this purchasing and recording system will make the payment process easier, avoid mistakes, and can streamline time.
\end{abstract}

Keywords: Credit Purchasing, MySQL, Web.

\begin{abstract}
ABSTRAK
CV Cipta Grafika merupakan sebuah perusahaan yang bergerak dalam bidang percetakan, untuk kebutuhan bahan baku percetakannya perusahaan ini membeli secara tunai maupun kredit. Pada penelitian ini peneliti akan membahas tentang proses pembelian bahan percetakan secara kredit, karena dalam proses ini aplikasi yang ada belum memberikan hasil yang maksimal yaitu sering adanya kesalahan dalam penyajian data atau informasi. Peneliti akan membuat sistem pembelian kredit dan pencatatan hutang berbasis web dengan $M y S Q L$ sebagai database nya. Hasil keluaran dari sistem ini adalah pembayaran kewajiban kepada pihak suplier yang akan jatuh tempo serta laporan pencatatan hutang suplier dapat terpantau. Dibuatnya sistem pembelian dan pencatatan ini diharapkan dapat mempermudah dalam melakukan proses pembayaran, terhindar dari kesalahan, dan dapat mengefektifkan waktu.
\end{abstract}

Kata Kunci: Pembelian Kredit, MySQL, Web.

\section{PENDAHULUAN}

Berkembang pesatnya usaha bisnis di Indonesia pada khususnya di Karawang mendorong perusahaan menengah untuk berkembang mengikuti kemajuan teknologi informasi. Kemajuan teknologi informasi mendorong perusahaan untuk ikut mengembangkan sistem informasi pada perusahaan hingga mempunyai sistem informasi yang baik dan efektif yang dapat membantu manajemen dalam pengambilan keputusan demi tercapainya tujuan utama perusahaan.

CV Cipta Grafika berdiri pada tahun 1994 merupakan salah satu perusahaan menengah yang bergerak dalam usaha desain grafis serta menyediakan bahan-bahan percetakan. Saat ini CV Cipta Grafika dalam melakukan pencatatan transaksi khususnya pada saat pembelian bahan percetakan secara kredit masih menggunakan cara manual yaitu dicatat melalui aplikasi Microsoft Excel pada seluruh kegiatan usahanya, seperti pembuatan Purchase Requesition (PR) dan Purchase Order (PO), sehingga sering terdapat kesalahan dalam penginputan data yang mengakitbatkan kesalahan dalam pembuatan laporan. Selain itu, keterbatasan jumlah karyawan pada CV Cipta Grafika, terdapat karyawan yang merangkap beberapa perkerjaan, seperti kasir dan bagian akuntansi atau bagian pembelian dan bagian penjualan yang seharusnya menjadi dua bagian pekerjaan yang terpisah. Hal ini menyebabkan tidak teraturnya pembagian jobdesc karyawan. Permasalahan lain yang terjadi adalah pada bagian pencatatan kredit yaitu tagihan suplier tidak terjadwal dengan rapih sehingga melawati batas tagihan, dan pada bagian produksi sering terjadi permintaan bahan baku yang tidak terjadwal, yang mengakibatkan stok barang menumpuk. Hal ini menyebabkan keterlambatan 
pembayaran yang mengakibatkan suplier tidak bisa mengirimkan bahan baku karena ada penguncian order.

Berdasarkan permasalahan di atas maka peneliti tertarik melakukan penelitian untuk membuat program aplikasi perancangan pembelian dan pencatatan pembelian bahan percetakan secara kredit berbasis web dengan menggunakan MySQL Server sebagai databasenya. Sistem akuntansi pembelian terkomputerisasi ini dibuat dengan harapan dapat menggantikan sistem yang lama, sehingga mampu menangani semua prosedur yang terdapat dalam sistem akuntansi pembelian.

\section{KAJIAN LITERATUR}

\section{Pengertian Sistem}

Menurut Diana \& Setiawati (2011) dalam (Samuna, Sabijono \& Walandouw, 2017), sistem merupakan serangkaian bagian yang saling tergantung dan bekerja sama untuk mencapai tujuan tertentu. Sedangkan menurut Mulyadi (2016) dalam (Ekananta, 2018) sistem adalah suatu jaringan prosedur yang dibuat menurut pola yang terpadu untuk melaksanakan kegiatan pokok perusahaan.

\section{Pengertian Informasi}

Menurut Sutanta (2004) dalam (Astuti, 2013), informasi merupakan hasil pengolahan data sehingga menjadi bentuk yang penting bagi penerimanya dan mempunyai kegunaan sebagai dasar dalam pengambilan keputusan yang dapat dirasakan akibatnya secara langsung saat itu juga atau secara tidak langsung pada saat mendatang.

\section{Kualitas Informasi}

Menurut Ladjamuddin (2010) dalam (Arnomo, 2018) kualitas informasi ditentukan oleh beberapa faktor, yaitu :

1. Relevan (Relevancy)

Seberapa jauh tingkat relevansi informasi tersebut terhadap kenyataan kejadian masa lalu, kejadian hari ini dan kejadian yang akan datang.

2. Akurat (Accuracy)

Suatu informasi dikatakan berkualitas jika seluruh kebutuhan informasi tersebut telah tersampaikan (completeness), seluruh pesan telah benar/sesuai (correctness), serta pesan yang disampaikan sudah lengkap atau hanya sistem yang diinginkan oleh user (security).

3. Tepat waktu (Timeliness)
Berbagai proses dapat diselesaikan dengan tepat waktu, laporan-laporan yang dibutuhkan dapat disampaikan tepat waktu.

4. Ekonomis (Economy)

Informasi yang dihasilkan mempunyai daya jual yang tinggi, serta biaya operasional untuk menghasilkan informasi tersebut minimal, informasi tersebut juga mampu memberikan dampak yang luas terhadap laju pertumbuhan ekonomi dan teknologi informasi.

5. Efisien (Efficiency)

Informasi yang berkualitas memiliki sintaks maupun kalimat yang sederhana (tidak berbelitbelit, tidak juga puitis, bahkan romantis), namun mampu memberikan makna dan hasil yang mendalam, atau bahkan menggetarkan setiap orang atau benda apapun yang menerimanya.

6. Dapat dipercaya (Reliability)

Informasi tersebut berasal dari sumber yang dapat dipercaya dan telah diuji tingkat kejujurannya.

\section{Pengertian Akuntansi}

Diana dan Setiawati (2011) dalam (Kholifin, 2017) dan (Hutahean, dkk., 2020) mendefinisikan akuntansi sebagai proses mengidentifikasi, mengukur, mencatat dan mengkomunikasikan peristiwa-peristiwa ekonomi dari suatu organisasi (bisnis maupun non bisnis) kepada pihak-pihak yang berkepentingan dengan informasi bisnis tersebut (pengguna informasi). Sedangkan menurut Mulyadi (2013) dalam (Wyanaputra, 2018) mendefinisikan akuntansi sebagai proses pencatatan, penggolongan, pemeriksaan dan penyajian dengan cara-cara tertentu, transaksi keuangan yang terjadi dalam perusahaan atau organisasi lain serta penafsiran terhadap hasilnya.

\section{Flowchart}

Menurut Indrajani (2011) dalam (Wyanaputra, 2018) bagan alir (flowchart) merupakan penggambaran secara grafik dari langkah-langkah dan urutan prosedur suatu program, biasanya mempermudah penyelesaian masalah yang khususnya perlu dipelajari dan di evaluasi lebih lanjut, digunakan terutama untuk alat bantu desain proses.

\section{Data Flow Diagram}

Yakub (2012) dalam (Hapsari \& Wardati, 2012) menjabarkan Data Flow Diagram (DFD) sebagai alat untuk membuat diagram yang serbaguna. Data flow diagram terdiri dari notasi penyimpanan (data store), proses (process), aliran data (flow data), 
dan sumber masukan (entity). Data Flow Diagram (DFD) terdiri dari beberpa model, diantaranya adalah :

a. Data Flow Diagram Context

b. Diagram Konteks

c. Data Flow Diagram Levelled

\section{Diagram Konteks}

Diagram konteks menurut Oetomo (2006) dalam (Rivai \& Purnama, 2015) merupakan pola penggambaran yang berfungsi untuk memperlihatkan intekasi sistem informasi dengan lingkungan dimana sistem tersebut ditempatkan.

\section{Entiry Relationship Diagram (ERD)}

Sebagaimana yang dikemukakan Edhy Sutanta (2011) dalam (Hapsari \& Wardati, 2012), Entity Relation Diagram (ERD) merupakan suatu model untuk menjelaskan hubungan antar data dalam basis data berdasarkan objek-objek dasar data yang mempunyai hubungan antar relasi. ERD untuk memodelkan struktur data dan hubungan antar data, untuk menggambarkannya digunakan beberapa notasi dan symbol.

\section{Kamus Data (Data Dictionary)}

Kendall (2003) dalam (Bachri, 2015) mendefinisikan kamus data sebagai hasil referensi data mengenai data, suatu data yang disusun oleh penganalisis sistem untuk pedoman selama melakukan analisis dan desain.

\section{System Development Life Cycle (SDLC)}

Krismiaji (2015) dalam (Sari, 2018) menyatakan bahwa System Development Life Cycle (SDLC) adalah salah satu metode pengembangan sistem informasi yang popular pada saat sistem informasi pertama kali dikembangkan yang dilakukan oleh analisis sistem dan programmer untuk membangun sebuah sistem informasi. Kemudian Simarmata (2010) dalam (Sofyan, Puspitorini, \& Yulianto, 2016) mengemukakan bahwa model proses pengembangan perangkat lunak SDLC mengacu pada proses yang digunakan pengembang dalam pengembangan perangkat lunak dan lain-lain.

\section{Basis Data (Database)}

Menurut Raharjo (2011) dalam (Suryadi \& Fauzi, 2015), Database didefinisikan sebagai kumpulan data yang terintegrasi dan diatur sedemikian rupa sehingga data tersebut dapat dimanipulasi, diambil, dan dicari secara cepat. Sedangkan, menurut Kustiyaningsih (2011) dalam (Nofyat, Ibrahim, \&
Ambarita, 2018) mendefinisikan bahwa database merupakan struktur penyimpanan data, untuk menambah, mengakses dan memproses data yang disimpan kedalam sebuah database komputer, agar data dapat tersimpan diperlukan sistem manajemen database seperti software MySQL Server.

\section{Word Elektrik Browser (Web)}

Dalam (Kuswara, 2018), Ardhana (2012) menyimpulkan bahwa Web adalah suatu layanan sajian informasi yang menggunakan konsep hyperlink (tautan), yang memudahkan surfer (sebutan para pemakai komputer yang melakukan browsing atau penelurusan informasi melalui internet).

\section{Hypertext Preprocessor (PHP)}

Menurut Sri Haryanti (2011) dalam (Siregar \& Sari, 2018), PHP (hypertext preprocessor) adalah sebuah bahasa pemrograman yang berbentuk scripting, sistem kerja dari program ini adalah sebagai interpreter bukan compiler. Selain itu Aris (2016) dalam (Siregar \& Sari, 2018) berpendapat bahwa PHP merupakan bahasa pemrograman script server-side yang bersifat open source. Script digunakan untuk membuat halaman web yang dinamis (up to date). Script terintegrasi dengan HTML dan berada pada server (server side HTML embedded scripting).

\section{Hyperlink Text Markup Language (HTML)}

Sibero (2013) dalam (Rukiastiandari, 2018) berpendapat bahwa HyperText Markup Language atau HTML adalah bahasa yang digunakan pada dokumen web sebagai bahasa untuk pertukaran dokumen web.

\section{Cascading Style Sheet (CSS)}

Menurut Saputra (2013) dalam (Handayani, Bin Taher, Usman, \& Ambarita, 2019) kepanjangan dari CSS adalah Cascading Style Sheet yang merupakan suatu bahasa pemrograman suatu bahasa pemrograman web yang digunakan untuk mengendalikan dan membangun berbagai komponen dalam web sehingga tampilan web akan lebih rapi, terstruktur, dan seragam.

\section{MySQL}

Sibero (2013) dalam (Sudarmaji, 2019) berpendapat bahwa MySQL atau dibaca My Sekuel adalah suatu RDBMS (Relational Database Management System) yaitu aplikasi sistem yang menjalankan fungsi pengolahan data. Selain itu Priyanto dan Jauhari (2015) pada (Sidik, Sutarman, \& 
Marlenih, 2017) menjelaskan bahwa MySQL adalah salah satu aplikasi DBMS yang sudah sangat banyak digunakan oleh para pemrogram aplikasi web. Contoh DBMS lainnya adalah: PostgreSQL (freeware), SQL Server, MS Access dari Microsoft, DB2 dari IMB, Oracle dan Oracle Crop, Dbase, FoxPro, dsb.

\section{PhpMyAdmin}

Menurut Su Rahman (2013) dalam (Kostaman \& Sumaryana, 2018) PhpMyadmin adalah sebuah software berbasis pemrograman PHP yang dipergunakan sebagai administrator MySQL melalui browser (web) yang digunakan untuk managemen database.

\section{Xampp}

Dalam (Pambudi, 2013) Kurniawan (2009) memaparkan bahwa XAMPP merupakan tool yang menyediakan paket perangkat lunak ke dalam satu buah paket. Dengan menginstal XAMPP maka tidak perlu lagi melakukan instalasi dan konfigurasi web server apache, PHP, dan MySQL secara manual. Selain itu Nugroho (2008) dalam (Jusmawati, 2017) berpendapat XAMPP merupakan paket PHP yang berbasis open source yang dikembangkan oleh sebuah komunitas open source.

\section{Sublime Text}

Bos (2014) menjelaskan dalam (Pahlevi, Mulyani, \& Khoir, 2018) Sublime Text merupakan salah satu text editor yang sangat powerful yang dapat meningkatkan produktivitas dan mengembangkan kualitas kode yang tinggi.

\section{Pembelian}

Menurut (Mulyadi, 2010), pembelian merupakan suatu tindakan untuk mendapatkan barang atau jasa yang kemudian akan dipeguanakn sendiri atau di jual kembali, pembelian biasanya dilakukan minimal dua pihak atu lebih atau yang sering disebut sebagai penjual dan pembelian, Pembelian dapat dibedakan menjadi dua jenis yaitu pembelian secara cash dan pembelian secara credit.

\section{Sistem Pembelian Kredit}

Pembelian kredit menurut (Mulyadi, 2010), merupakan pembelian yang dilakukan oleh perusahaan yang dalam pembayarannya dilakukan secara bertahap atau secara angsuran kepada pemasok. Pembelian kredit adalah salah satu cara agar perusahaan dapat terus menjalankan kegiatan perusahaanya, dengan sistem pembelian kredit yang baik, diharapkan masalah persediaan yang menumpuk, penjadwalan pembayaran hutang dan giro yang dibayarkan, karena kurangnya informasi dapat dihindari.

\section{Sistem dan Prosedur Retur Pembelian}

Menurut (Mulyadi, 2010), sistem retur pembelian digunakan dalam perusahaaan untuk pengembalian barang yang sudah dibeli kepada pemasoknya. Barang yang sudah diterima pemasok terkadang tidak sesaui dengan barang yang dipesan menurut surat order pembelian. Ketidak sesuaian itu terjadi kemungkinan karena barang yang diterima tidak cocok dengan spesifikasi yang tercantum dalam surat order pembelian, barang, mengalami kerusakan dalma pengiriman atau barang yang diterima melewati tanggal pengiriman yang dijanjikan.

\section{Persediaan}

Menurut Hanafi (2010) dalam (Norawati, 2019) berpendapat bahwa persediaan dibagi menjadi beberapa jenis persediaan yaitu persediaan bahan mentah, persediaan bahan setengah jadi dan persediaan barang jadi (barang dagangan). Bahan mentah merupakan bahan yang akan digunakan untuk memproduksi barang dagangan. Barang setengah jadi merupakan barang yang belum selesai sepenuhnya menjadi barang dagangan. Sedangkan, barang jadi merupakan barang yang sudah selesai dikerjakan dan siap untuk dijual.

\section{Hutang}

Dalam (Jusuf, 2014) berpendapat bahwa kewajiban (Liabilities) adalah hutang perusahaan masa kini yang timbul dari peristiwa masa lalu, penyelesaian diharapkan mengakibatkan arus keluar dari sumber daya perusahaan yang mengandung manfaat ekonomi. Intinya, kewajiban adalah utang yang harus dilunasi perusahaan. Ada beberapa jenis yang ditemukan dalam kategori ini adalah :

1. Pinjaman Jangka Pendek Dari Bank

Yaitu baki debet (loan Outsanding) perusahaan pada bank yang memiliki jangka waktu maksimum satu tahun. Yang temasuk dalam golongan ini umumnya adalah pinjaman untuk modal kerja (working capital loan).

2. Utang Dagang (Account Payable)

Yaitu utang perusahaan pada pihak lain yang timbul akibat adanya transaksi yang berkaitan dengan bisnis utamanya. Utang dagang tidak lain adalah kredit yang diperoleh perusahaan dari supplier. Utang yang diperoleh dari pihak lain, 
misalnya pemegang saham, tidak dicatat sebagai utang dagang.

3. Utang Pajak (Tax Payable)

Pajak yang masih harus dibayar oleh perusahaan. Utang pajak ini bisa macam-macam, misalnya utang PPN (Pajak Pertambahan Nilai).

4. Biaya yang masih harus dibayar (Accrual Expenses)

Yaitu biaya yang harus dibayarkan perusahaan kepada pihak lain yang telah diakui sebagai pengeluaran biaya tetapi belum dibayarkan.

\section{METODE PENELITIAN}

Metode perancangan aplikasi yang digunakan dalam penelitian ini adalah SLDC (Software Development Life Cycle). Rosa dan M.Shalahuddin (2013) dalam (Sabaruddin \& Murni, 2018) mengemukakan bahwa dengan model SDLC air terjun (waterfall) sering juga disebut model sekuensial linier (sequential linear) atau alur hidup klasik (classic life cycle) menyediakan pendekatan alur hidup perangkat lunak secara sekuensial atau terurut dimulai dari analisis, desain, pengodean, pengujian dan tahap pendukung (support). Pada gambar 1 dibawah ini merupakan model air terjun dengan fase langkahlangkahnya:

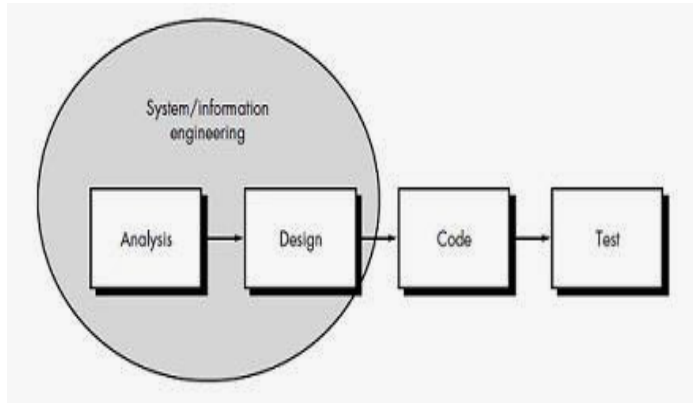

Gambar 1. Ilustrasi SDLC Model Waterfall

\section{Analisis Kebutuhan Perangkat}

Tahapan ini adalah kegiatan yang dilakukan untuk menganalisa kebutuhan sistem berjalan yang bertujuan menspesifikasikan kebutuhan perangkat lunak seperti apa yang dibutuhkan oleh pengguna/use. Penelitian yang dilakukan oleh peneliti diantaranya :

a. Observasi

Pengumpulan data yang dilakukan dengan cara mengamati dan mempelajari proses dari objek secara lansung terhadap bagian yang terkait didalam proses pemesanan dan pembelian bahan secara kredit sehingga peneliti dapat memahami sistem yang berjalan di Percetakan Cipta Grafika.

b. Wawancara/Interview
Teknik pengumpulan data dengan cara berkomunikasi tanya jawab untuk mendapatkan informasi secara langsung kepada suatu pihak yang terkait. Proses pengumpulan data, keterangan, dan bahan bahan-bahan yang diperlukan sebagai pembahasan dalam penelitian.

c. Studi Pustaka/Library Research

Studi pustaka merupakan proses pengumpulan data yang berkaitan dengan masalah yang diteliti. Sumber-sumber referensi tertulis yang bersumber pada buku-dan dokumen-dukumen yang didapatkan dari perpustakaan serta sumber lainnya seperti internet browser.

\section{Desain}

Desain perangkat lunak adalah proses multi langkah yang fokus pada desain pembuatan program perangkat lunak termasuk struktur data, Tahap ini mentranslasi kebutuhan perangkat lunak dari tahap analisis kebutuhan ke representasi desain agar dapat diimplementasikan menjadi program pada tahap selanjutnya. Desain perangkat lunak yang dihasilkan pada tahap ini juga perlu didokumentasikan, metode perancangan yang akan digunakan peneliti dalam menyusun tugas akhir ini adalah perancangan Flow document, DFD (data flow diagram), kamus data, ERD (Entity Relationship Diagram) dan pembuatan bagan yang terstuktur dengan rancangan masukan dan keluaran pada sistem yang sedang berjalan.

\section{Pembuatan Kode Program}

Setelah tahap desain, selanjutnya adalah pembuatan kode program dimana desain ditranslasikan ke dalam aplikasi pemrograman perangkat lunak. Peneliti akan merancang sistem dengan bahasa pemograman web dengan aplikasi Adobe Dreamweaver CS6 dan MySQL Server sebagai databasenya.

\section{Pengujian}

Pengujian fokus pada perangkat lunak secara dari segi lojik dan fungsional dan memastikan bahwa semua bagian sudah diuji. Hal ini dilakukan untuk meminimalisir kesalahan (error) dan memastikan keluaran yang dihasilkan sesuai yang diinginkan.

\section{HASIL DAN PEMBAHASAN}

\section{Analisis dari sistem yang diajukan}

Dari permasalahan yang ada dan dari analisis yang telah dilakukan, dapat dibuat suatu usulan sistem baru yang dituangkan kedalam bentuk Flowmap, 
diagram rinci, Diagram Overview, ERD sebagai berikut:

a. Flowmap Usulan

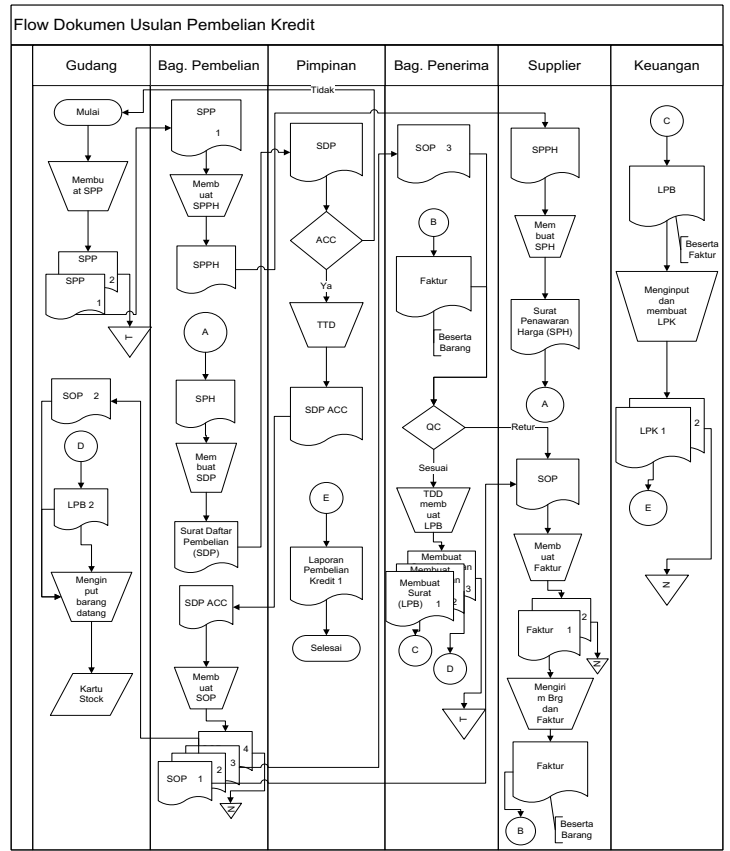

Gambar 2. Flowmap Usulan

Gambar 2 merupakan gambaran secara detail mengenai alur sistem yang peneliti usulkan dalam bentuk Flowmap.

b. Diagram Rinci

d. Entity Relationship Diagram (ERD)

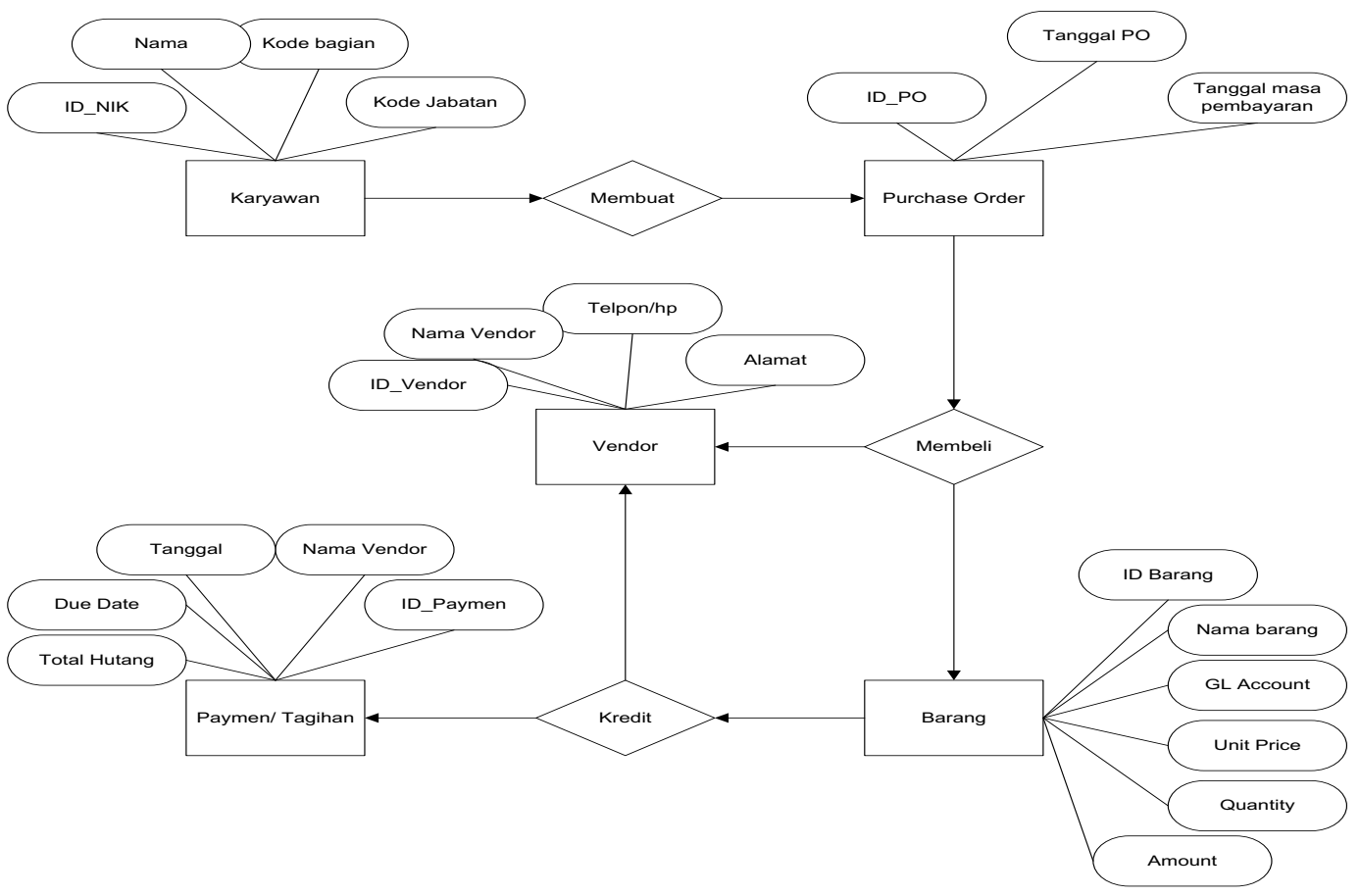

Gambar 5. Entity Relationship Diagram (ERD)

Gambar 5 merupakan ERD dari entitas serta atribut-atribut yang akan digunakan dalam pembuatan database.

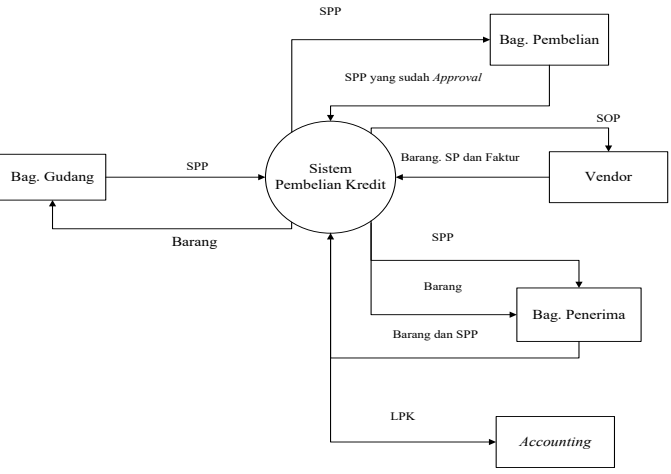

Gambar 3. Diagram Rinci Pembelian Bahan secara Kredit

Gambar 3 merupakan gambaran pembelian bahan secara kredit dalam bentuk diagram rinci.

c. Diagram Overview

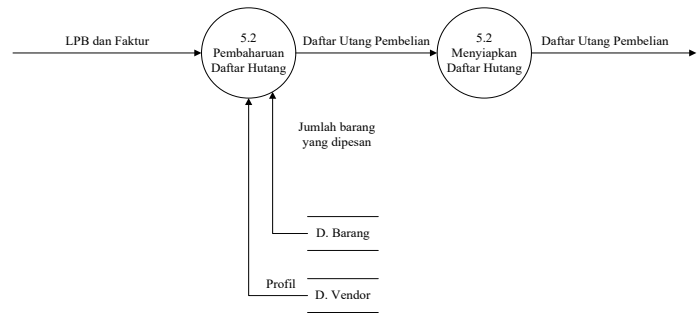

Gambar 4. Diagram Overview Pembelian Gambar 4 merupakan alur dari sistem pembelian yang dipaparkan dalam bentuk diagram overview. 


\section{Implementasi}

Implementasi sistem membahas mengenai tahapan lanjutan pelaksanaan dan penerapan dari sistem yang sudah dianalisis terlebih dahulu. Setelah dilakukan penerapan maka sistem tersebut akan dilakukan pengujian untuk mengetahui apakah sistem dapat berjalan dengan baik atau tidak.

a. Tampilan Halaman Login

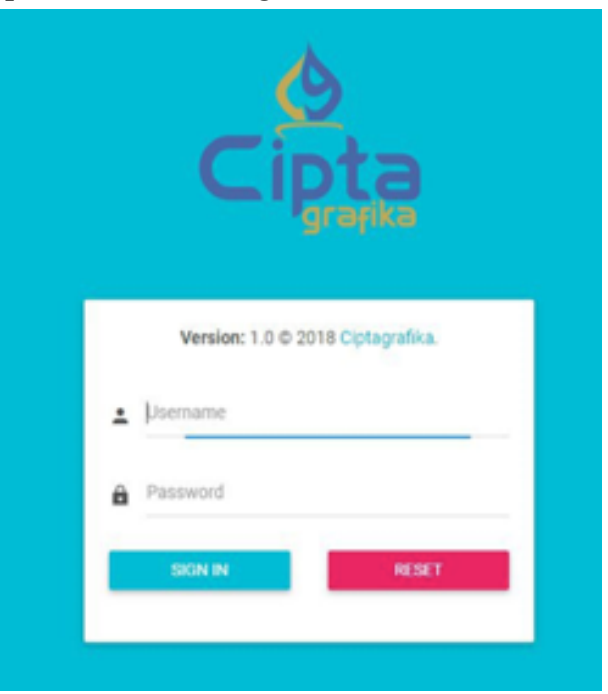

Gambar 6. Halaman Login

Halaman login merupakan halaman yang digunakan untuk dapat masuk ke dalam halaman utama. User harus memasukan username dan password yang tepat agar dapat masuk ke halaman utama. Halaman login dapat dilihat pada gambar 6 .

b. Tampilan Menu Utama

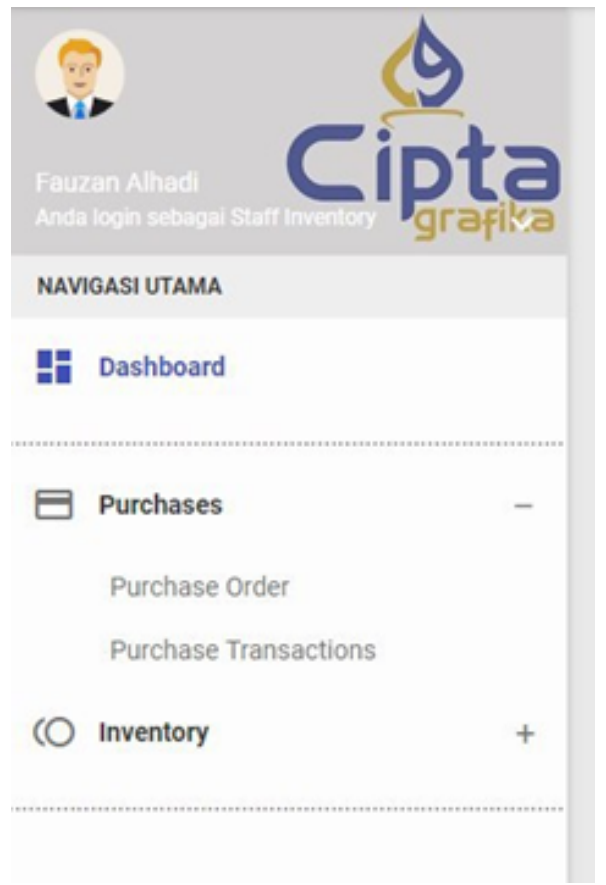

Gambar 7. Halaman Menu Utama
Gambar 7 merupakan Halaman Menu utama dimana terdapat pilihan menu sebagai berikut:

1. Dashboard: apabila di klik maka akan menampilkan submenu yaitu Purchases, Purchase order, purchase transaction, inventory.

2. Purchases: submenu dari master apabila di klik maka akan menampilkan dua item;
a. Purchases Order
b. Purchases Transaction

3. Purchase Order: submenu dari master apabila di klik maka akan menampilkan form untuk memasukan data barang yang dipesan kepada vendor.

4. Purchase Trasaction: submenu dari master apabila di klik maka akan menampilkan form untuk melihat inputan purchase order dan masuk pencatatan payment/ hutang secara otmatis bila barang sudah datang.

5. Inventory: submenu dari master apabila di klik maka akan menampilkan form untuk memasukan data barang.

6. All Item: submenu dari master apabila di klik maka akan menampilkan form untuk masukan data barang baru

c. Tampilan Data Purchases Order

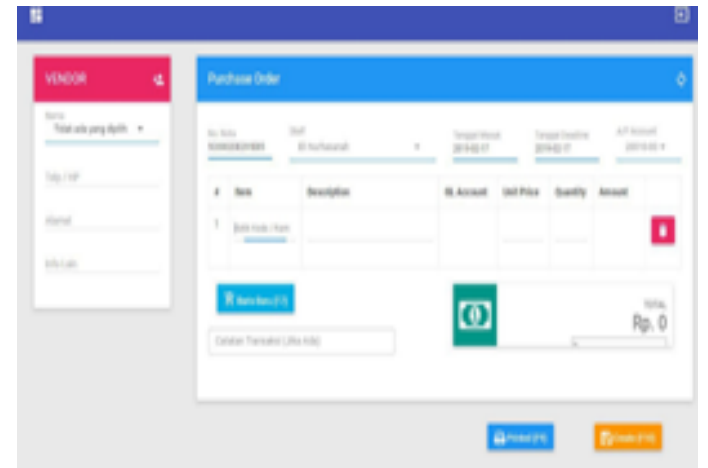

Gambar 8. Halaman Data Purchases Order

Gambar 8 merupakan tampilan halaman input data Purchases Order, digunakan sebagai sistem dengan memasukan Vendor_id, Telp, Alamat, Item, Description, GL Account, Unit Price, Quantity, Amount. 
d. Tampilan Data Tambah Item Barang

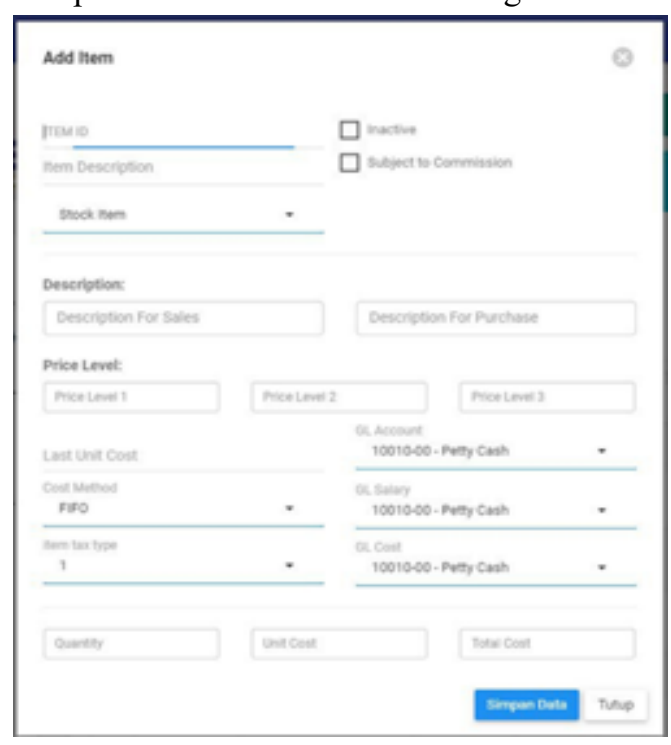

Gambar 9. Form Data Tambah Item Barang

Gambar 9 adalah tampilan form input data tambah item Barang. Form Tambah item barang digunakan sebagai sistem dengan memasukan kode Barang baru.

e. Tampilan Data Purchase Transaction

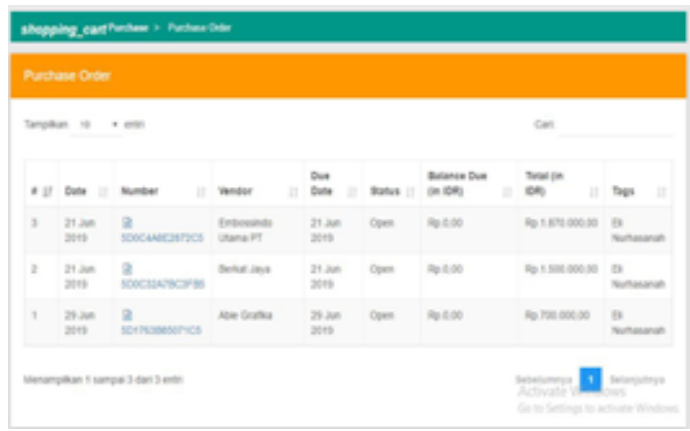

Gambar 10. Form Data Purchase Transaction

Gambar 10 adalah tampilan form input data bagian. Form bagian digunakan sebagai sistem untuk melihat inputan purchase order dan masuk pencatatan payment/ hutang secara otmatis bila barang sudah tanda terima Faktur.

f. Tampilan Data Transaksi

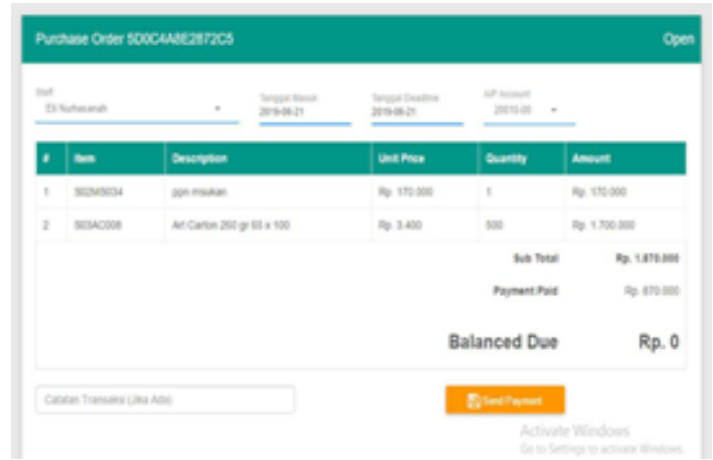

Gambar 11. Form Data Transaksi
Gambar 11 adalah tampilan form data Transaksi. Transaksi ini digunakan sebagai sistem pembelian yang akan dibayar.

g. Tampilan Data Transaksi

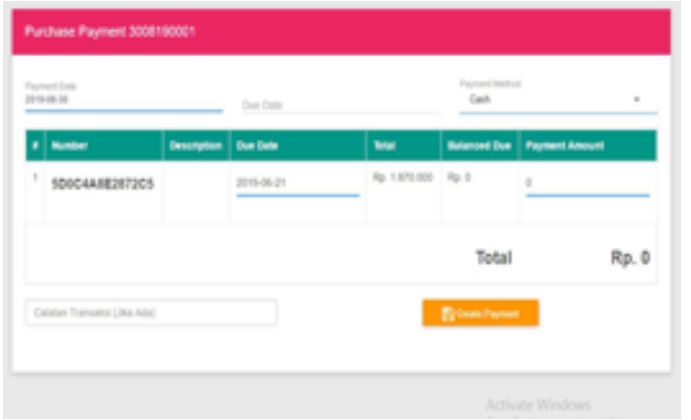

Gambar 12. Form Data Payment

Gambar 12 adalah tampilan form data Payment. Transaksi ini digunakan sebagai system pembayaran terhadap vendor.

\section{KESIMPULAN}

Penelitian yang dilakukan peneliti adalah pada CV Cipta Grafika mengenai pembelian dan pencatatan kredit. Sistem yang sedang berjalan, belum dapat mengakses data yang berhubungan dengan sistem pembelian kredit, baik dari proses pemesanan order bahan maupun proses pencatatan hutang. Sehingga tagihan dari suplier belum terkontrol dengan baik dan stok barang pembeliannya tidak terjadwal. Berdasarkan permasalah tersebut, peniliti membangun sistem komputerisasi akuntansi pembelian kertas secara kredit berbasis web untuk memiminalisir kesalahan dalam penginputan data transaksi serta untuk mempermudah proses pencatatan, pembuatan laporan dan kegiatan lainnya pada CV Cipta Grafika dengan lebih efektif dan efisien.

\section{DAFTAR PUSTAKA}

Arnomo, S. A. (2018). Mengukur Ketepatan Kualitas Informasi Sistem Tracer Dan Tracking Jasa Kurir. Computer Based Information System Journal, 6(1), 56-62. https://doi.org/10.33884/cbis.v6i1.641

Astuti, P. D. (2013). Sistem Informasi Penjualan Obat Pada Apotek Jati Farma Arjosari. Indonesian Jurnal on Computer Science - Speed (IJCSS), 10(1), 142-147. https://doi.org/http://dx.doi.org/10.3112/speed.v $3 \mathrm{i} 4.1217$

Bachri, O. S. (2015). Sistem Informasi Pengolahan Data Nilai Murid Di SMA Negeri 4 Kota 
Cirebon. Jurnal Digit, 5(1), 24-33.

Ekananta, D. P. (2018). Monopoli Dan Persainganm Usaha Tidak Sehat Pada Perdagangan Produk Air Minum Dalam Kemasan. Skripsi. Jember: Universitas Jember.

Handayani, T., Bin Taher, Y. S., Usman, A. H., \& Ambarita, A. (2019). Aplikasi Pemeriksaan Biaya Instalasi Tegangan Listrik Rendah Berbasis Web Pada PT. PPILN Maluku Utara. IJIS - Indonesian Journal On Information System, 4(1), 32-40. https://doi.org/10.36549/ijis.v4i1.51

Hapsari, S., \& Wardati, I. U. (2012). Rancang Bangun Sistem Informasi Pembayaran Dan Tabungan Siswa Pada Bank Mini Artha Mandiri Sekolah Menengah Kejuruan (SMK) Negeri Pringkuku Pacitan. Speed - Sentra Penelitian Engineering Dan Edukasi, 3(2), 55-64. https://doi.org/10.3112/SPEED.V3I2.925

Hutahean, L., Sagala, E. \& Jamaluddin. (2020). Sistem Informasi Akuntansi Pelayanan Jasa Rawat Jalan dan Rawat Inap pada Rumah Sakit Umum Mitra Sejati Medan. Majalah Ilmiah METHODA, 10(1), 9-15.

Jusuf, J. (2014). Analisis Kredit Untuk Account Officer. Jakarta: Gramedia Pustaka.

Jusmawati. (2017). Aplikasi E-Commerce Pada Stand Ifa Kota Merauke. Jurnal Ilmiah Teknik dan Informatika, 2(1), 14-20.

Kholifin, A. (2017). Analisis Perancangan Sistem Informasi Pembelian Untuk Meningkatkan Pengendalian Intern UD. Alfa Omega. EJournal Akuntansi "EQUITY", 3(2),112-122.

Kostaman, N., \& Sumaryana, Y. (2018). Aplikasi pemesanan tiket oto bus budiman berbasis online. Jumantaka, 1(1), 121-130.

Kuswara, H. (2018). Sistem Informasi Akademik Berbasis Web Pada Special English Converstation By Mr.T Bekasi. Jurnal Bianglala Informatika, 6(1), 4.

Mulyadi. (2010). Sistem Akuntansi. Jakarta: Salemba Empat.
Nofyat, Ibrahim, A., \& Ambarita, A. (2018). Information Systems Water Customers Complaints Web-Based On. Ijis, 3(April), 10.

Norawati, M. F. A. and S. (2019). Analisis Pengendalian Persediaan Bahan Baku dengan Menggunakan Metode Period Order Quantity(POQ) pada Usaha Roti Kampar Bakery. Jurnal Riset Manajemen Indonesia, 1(1), 1-5.

Pahlevi, O., Mulyani, A., \& Khoir, M. (2018). Sistem Informasi Inventori Barang Menggunakan Metode Object Oriented Di PT. Livaza Teknologi Indonesia Jakarta. Jurnal PROSISKO, 5(1).

Pambudi, A. (2013). Implementasi Model Perangkat Lunak Pelayanan Informasi Kegiatan Belajar Mengajar Tingkat Slta Dengan Berbasis Operating System Android. Jurnal Ilmu Komputer, 9(2), 108-120. https://doi.org/10.1007/s10853-009-3545-1

Rivai, D. A., \& Purnama, B. E. (2015). Pembangunan Sistem Informasi Pengolahan Data Nilai Siswa Berbasis Web Pada Sekolah Menengah Kejuruan (SMK) Miftahul Huda Ngadirojo. Indonesian Journal on Networking and Security, 3(2), 2302-5700.

Rukiastiandari, S. (2018). Rancang Bangun Aplikasi Penjualan Lukisan (Studi Kasus Toko Cipadu). Prosiding Seminar Nasional Teknologi, pp.783793.

Sabaruddin, R., \& Murni, S. (2018). Rancang Bangun Aplikasi Asuransi Mobil Dengan Pendekatan Metode Waterfall. JUTIM (Jurnal Teknik Informatika Musirawas), 3(2), 99-108. https://doi.org/10.32767/jutim.v3i2.365

Samuna, J. N., Sabijono, H., \& Walandouw, S. K. (2017). Evaluasi Penerapan Sistem Pengendalian Intern Persediaan Barang Dagangan Pada Toko Mahkota Diesel Manado. Going Concern : Jurnal Riset Akuntansi, 12(1), 294-302.

https://doi.org/10.32400/gc.12.01.17282.2017

Sari, N. Z. M. (2018). Pengaruh Strategi Bisnis, Metoda Pengembangan Sistem (System Development Life Cycle), Terhadap Kualitas 
Sistem Informasi Akuntansi (Survei Pada PT

Len Industri Persero-BUMN Industri Strategis

di Indonesia). Sosiohumanitas, 20(2), 39-53.

https://doi.org/10.36555/sosiohumanitas.v20i2.1

10

Sidik, A., Sutarman, \& Marlenih. (2017). Perancangan Sistem Informasi Penjualan Perumahan Citra Raya. Jurnal Sisfotek Global, 7(1), 56-65.

Siregar, H. F., \& Sari, N. (2018). Rancang Bangun Aplikasi Simpan Pinjam Uang Mahasiswa Fakultas Teknik Universitas Asahan Berbasis Web. Jurnal Teknologi Informasi, 2(1), 53. https://doi.org/10.36294/jurti.v2i1.409

Sofyan, A. A., Puspitorini, P., \& Yulianto, M. A. (2016). Aplikasi Media Informasi Sekolah Berbasis SMS Gateway Dengan Metode SDLC (System Development Life Cycle). Jurnal Sisfotek Global, 6(2), 1-7.

Sudarmaji. (2019). Perancangan Responsive Layanan Sistem Informasi Perkuliahan Online terhadap Mahasiswa dan Dosen Pengampu Matakuliah. SIMADA (Jurnal Sistem Informasi dan Manajemen Basis Data), 2(1), 80-90.

Suryadi, E., Mustamassikin, \& Fauzi, R. H. (2015). Pemodelan Data Pada Mobile Payment Information System of the Sport Hall Centre. Prosiding Seminar Nasional Informatika (SNIf) 2015, pp.258-264.

Wyanaputra, J. (2018). Sistem Akuntansi Penggajian pada CV. Bakung Abadi Express Pekanbaru. Jurnal Ilmu Komputer Dan Bisnis, 9(1), 19101923. https://doi.org/10.1017/CBO9781107415324.00 4 